\title{
sciendo
}

DOI 10.2478/sbe-2019-0051

SBE no. 14(3) 2019

\section{BITCOIN IN THE SCIENTIFIC LITERATURE - A BIBLIOMETRIC STUDY}

\author{
ORĂȘTEAN RAMONA \\ Lucian Blaga University of Sibiu, Romania \\ MĂRGINEAN SILVIA CRISTINA \\ Lucian Blaga University of Sibiu, Romania \\ SAVA RALUCA \\ Lucian Blaga University of Sibiu, Romania
}

\begin{abstract}
:
Since 2012, there has been growing interest in bitcoin scientific research from different fields, including computer science and engineering, economics, business and finance, law and regulatory. The purpose of this paper is to evaluate bitcoin literature based on the structures and networks of science, as a first step in the research of this new phenomenon. Analysing the growing scientific literature on bitcoin published between 2012 and 2019, we provided useful insights on academic research in this field regarding publication year, type and category, authors, journals and citations. The source of the 887 documents which support the study was Web of Science Core Collection. Using VOSviewer software we have designed bibliometric maps based on text and bibliographic data. Our study provides a knowledge area map that identifies and evaluates the links between authors and countries distribution, the conceptual structure of the field, the structure and connections of most cited papers and journals. Resuming our findings, we note a concentration of the interest on some keywords (bitcoin, cryptocurrency, blockchain) and on some influential authors (with more than 100 citations per article). As a pure expression of digital economy, the research on bitcoin as an economic concept counts only $33.5 \%$ from the total contributions in the field.
\end{abstract}

Key words: bitcoin, bibliometric study, scientific literature, VOSviewer, knowledge area map

\section{Introduction}

Cryptocurrencies and blockchain are topics of interest for both researchers from different fields - computer science and engineering, economics, business and finance, law and regulatory - and investors and policy makers. Now there are several hundreds of cryptocurrencies and many applications of blockchain technology. 
This research is limited to bitcoin, as the most used cryptocurrency and having the highest market capitalization. Bitcoin is a digital money that it is not issued and supervised by a central bank or other authority. It uses a peer-to-peer technology what means that a decentralized network managed these tasks collectively and payment transactions are stored in a data structure (blockchain). Bitcoin is the first decentralized cryptocurrency introduced in 2009. The bitcoin market capitalization increased from 0.04 billion US dollars in the first quarter of 2012 to around 165 billion US dollars in the fourth quarter of 2019 (Figure 1). Bitcoin recorded price fluctuations larger than other currency, with a minimum of 68.43 US dollars in 5 July 2013 and a maximum of 19497 US dollars in 16 December 2017, and a present value of 7300 US dollars in 2 December 2019 (CoinMarketCap).

Figure 1. Bitcoin price and market capitalization in 2012-2019

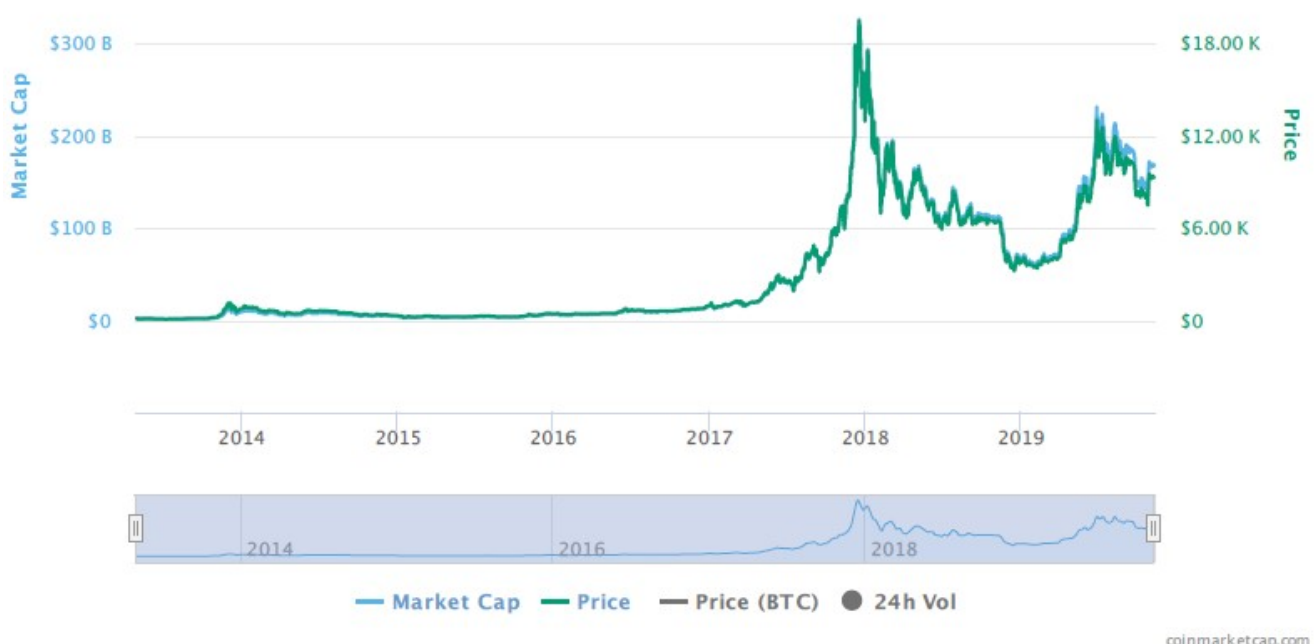

Considering these evolutions, since 2013 bitcoin has become a hot topic in the world financial news. In the same time, there has been growing interest in bitcoin scientific research. The rest of the paper is structured as follows. The next section presents the data and methodology. Section 3 provides the results and interpretation. Section 4 maps the scientific literature on bitcoin using VOSviewer program. Finally, Section 5 concludes.

\section{Data and methodology}

We used the standard workflow for science mapping described by Aria \& Cuccurullo (2017).

a. study design;

This research is a bibliometric analysis that aims to do a systematic review of the scientific literature on bitcoin. We identified several articles that study the bitcoin literature, for different time periods and using various databases and software tools. 
The paper that first introduced bitcoin in 2008 is "Bitcoin: A Peer-to-Peer Electronic Cash System" (Nakamoto, 2008). In January 2009, Satoshi Nakamoto released the first bitcoin software that launched the network and the first units of the bitcoin.

Liu (2016) collected 253 articles related to bitcoin from the Scopus database and model the bitcoin research in a PEST analysis structure (political, economic, social, and technological).

Holub \& Johnson (2018) made a comprehensive search of the bitcoin literature (13507 results) using different data sources (Web of Science, Scopus, SpringerLink, EconPapers, SSRN etc.) and selected 1206 papers for a detailed analysis on six disciplines (technology, economics, finance, regulation, taxation and accounting).

Merediz-Sola \& Bariviera (2019) analysed metadata of all the papers indexed in the Web of Science Core Collection that contained bitcoin as topic for the period 2012January 2019, in a total of 1162 documents.

b. data collection;

We collected the data from Web of Science Core Collection database (Clarivate Analytics). We searched for bitcoin as title and we found 911 results for the period 20122019.

We have imported data from Web of Science Core Collection and cleaned the data, excluding the records for 2020 (1 article) and in other languages than English (6 Spanish, 3 French, 3 Turkish, 2 Chinese, 2 Portuguese, 1 Croatian, 1 Czech, 1 Italian, 1 Japanese, 1 Polish, 1 Russian, 1 Slovak). Thus, we have constructed our database with 887 documents.

\section{c. data analysis;}

In our database we have filtered and analysed the data using criteria such as publication year, Web of Science document type, Web of Science category, authors, countries, journals and number of citations.

\section{d. interpretation;}

In this stage, we tried to interpret and describe the results of the research.

\section{e. data visualization.}

There are diverse software tools supporting bibliometric analysis. We have chosen VOSviewer software that support Web of Science files (van Eck \& Waltman, 2010) for constructing and visualization bibliometric maps.

\section{Results and interpretation}

Using our database with 887 documents, we have filtered and analysed the data using criteria such as publication year, Web of Science document type, Web of Science category, authors, countries, journals and number of citations.

Table 1 presents the evolution of the bitcoin publications in 2012-2019. We noticed that the number of papers has increased over time, particularly in the last two years. 
Table 1. Bitcoin papers published by year, 2012-2019

\begin{tabular}{|c|r|r|}
\hline Publication year & Number of papers & \% of total 887 \\
\hline 2019 & 228 & 25.71 \\
\hline 2018 & 240 & 27.06 \\
\hline 2017 & 140 & 15.78 \\
\hline 2016 & 103 & 11.61 \\
\hline 2015 & 96 & 10.82 \\
\hline 2014 & 67 & 7.55 \\
\hline 2013 & 12 & 1.35 \\
\hline 2012 & 1 & 0.11 \\
\hline
\end{tabular}

The article published in scientific journals is the type of document most used by the authors to present their results $(51.4 \%)$. On the second position is the Proceedings paper with $37.5 \%$ (Table 2 ).

Table 2. Bitcoin papers by Web of Science document type

\begin{tabular}{|l|r|r|}
\hline $\begin{array}{c}\text { Web of Science } \\
\text { document type }\end{array}$ & Number of papers & \% of total $\mathbf{8 8 7}$ \\
\hline Article & 456 & 51.41 \\
\hline Proceedings paper & 333 & 37.54 \\
\hline Editorial material & 47 & 5.30 \\
\hline Book chapter & 34 & 3.83 \\
\hline News item & 21 & 2.37 \\
\hline Book review & 15 & 1.69 \\
\hline Letter & 7 & 0.79 \\
\hline Review & 5 & 0.56 \\
\hline Book & 3 & 0.34 \\
\hline
\end{tabular}

We observed that Web of Science assigns papers to one or more research areas. However, bitcoin papers are concentrated around three main fields (Table 3): computer science (54.1\%); economics, business and finance (33.5\%); engineering (12.7\%).

Table 3. Bitcoin papers by Web of Science category

\begin{tabular}{|l|r|r|}
\hline \multicolumn{1}{|c|}{ Web of Science category } & $\begin{array}{c}\text { Number of } \\
\text { papers }\end{array}$ & \% of total $\mathbf{8 8 7}$ \\
\hline Computer science theory methods & 231 & 26.04 \\
\hline Computer science information systems & 170 & 19.17 \\
\hline Economics & 153 & 17.25 \\
\hline Business, Finance & 144 & 16.23 \\
\hline Engineering electrical electronic & 113 & 12.74 \\
\hline Computer science interdisciplinary applications & 76 & 8.57 \\
\hline
\end{tabular}

The top 10 productive authors based on publications' number are shown in Table 4. The most productive authors are Elie Bouri and David Roubaud, with 12 papers each, followed by Elli Androulaki with 10 papers. 
Table 4. Top 10 authors of bitcoin papers

\begin{tabular}{|l|r|}
\hline \multicolumn{1}{|c|}{ Authors } & \multicolumn{2}{c|}{$\begin{array}{c}\text { Number of } \\
\text { papers }\end{array}$} \\
\hline Bouri, E. & 12 \\
\hline Roubaud, D. & 12 \\
\hline Androulaki, E. & 10 \\
\hline Karame, G. & 9 \\
\hline Selmi, R. & 9 \\
\hline Bouoiyour, J. & 8 \\
\hline Gupta, R. & 8 \\
\hline Moore, T. & 8 \\
\hline Mullan, P.C. & 8 \\
\hline Tiwari, A.K. & 8 \\
\hline
\end{tabular}

According to Figure 2, USA is the country whose authors have published highest number of papers (23.8\%), followed by United Kingdom (9.4\%) and China (8.6\%).

Figure 2. Corresponding author's countries of bitcoin papers (\% of total 887 )

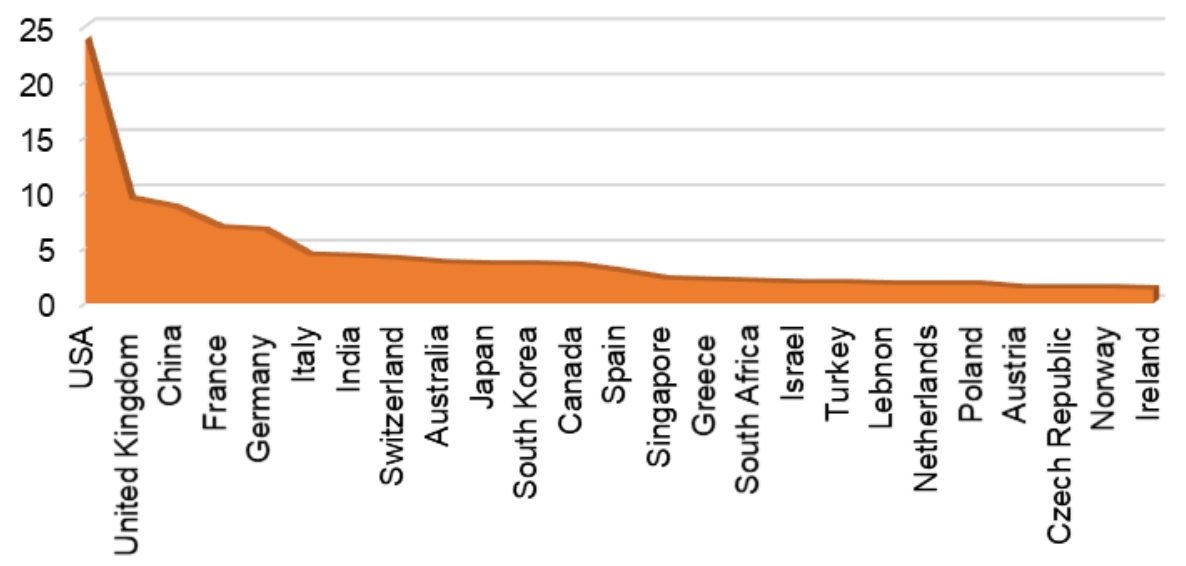

Table 5 shows top 10 main sources that have published bitcoin papers. Seven of them are journals (14.8\% of total 887 ) and reflect the interdisciplinarity of bitcoin research field: 4 economics journals - Finance Research Letters, Economics Letters, International Review of Financial Analysis, Research in International Business and Finance; 1 physics journal - Physica A-Statistical Mechanics and Its Applications; 1 multidisciplinary journal Plos One; 1 science and technology magazine - New Scientist. The other three are conference proceedings, with 91 papers published on bitcoin topic (10.2\% of total 887 ). 
Table 5. Top 10 sources of bitcoin papers

\begin{tabular}{|l|r|r|}
\hline \multicolumn{1}{|c|}{ Web of Sciences source title } & \multicolumn{1}{c|}{$\begin{array}{c}\text { Number of } \\
\text { papers }\end{array}$} & \% of total $\mathbf{8 8 7}$ \\
\hline Lecture Notes in Computer Science & 69 & 7.71 \\
\hline Finance Research Letters & 31 & 3.46 \\
\hline Economics Letters & 26 & 2.91 \\
\hline Physica A-Statistical Mechanics and Its Applications & 21 & 2.35 \\
\hline New Scientist & 17 & 1.90 \\
\hline Plos One & 13 & 1.45 \\
\hline International Review of Financial Analysis & 12 & 1.34 \\
\hline Research in International Business and Finance & 12 & 1.34 \\
\hline Financial Cryptography and Data Security FC 2014 Workshop & 11 & 1.23 \\
\hline Financial Cryptography and Data Security FC 2015 Workshop & 11 & 1.23 \\
\hline
\end{tabular}

Table 6 presents the list of 33 papers categorized as 'highly cited papers' in Web of Science (the top $1 \%$ of papers by field and publication year).

Table 6. `Highly cited` bitcoin papers (33) according to Clarivate Analytics

\begin{tabular}{|c|c|c|c|}
\hline Title & Authors & Source title & $\begin{array}{l}\text { Cita- } \\
\text { tions }\end{array}$ \\
\hline $\begin{array}{l}\text { Bitcoin and beyond: } \text { A technical survey on } \\
\text { decentralized digital currencies }\end{array}$ & $\begin{array}{l}\text { Tschorsch \& } \\
\text { Scheuermann (2016) }\end{array}$ & $\begin{array}{l}\text { IEEE Communications } \\
\text { Surveys and Tutorials }\end{array}$ & 192 \\
\hline $\begin{array}{l}\text { Bitcoin: economics, technology, and } \\
\text { governance }\end{array}$ & $\begin{array}{l}\text { Bohme, Christin, } \\
\text { Edelman, \& Moore } \\
\text { (2015) }\end{array}$ & $\begin{array}{l}\text { Journal of Economic } \\
\text { Perspectives }\end{array}$ & 175 \\
\hline The inefficiency of Bitcoin & Urquhart (2016) & Economics Letters & 155 \\
\hline $\begin{array}{l}\text { Speculative bubbles in Bitcoin markets? An } \\
\text { empirical investigation into the fundamental } \\
\text { value of Bitcoin }\end{array}$ & Cheah \& Fry (2015) & Economics Letters & 146 \\
\hline $\begin{array}{l}\text { Bitcoin, gold and the dollar - } A \text { GARCH } \\
\text { volatility analysis }\end{array}$ & Dyhrberg (2016a) & Finance Research Letters & 132 \\
\hline $\begin{array}{l}\text { Volatility estimation for Bitcoin: A comparison } \\
\text { of GARCH models }\end{array}$ & Katsiampa (2017) & Economics Letters & 109 \\
\hline The economics of BitCoin price formation & $\begin{array}{l}\text { Ciaian, Rajcaniova, \& } \\
\text { Kancs (2016) }\end{array}$ & Applied Economics & 103 \\
\hline $\begin{array}{l}\text { On the hedge and safe haven properties of } \\
\text { Bitcoin: Is it really more than a diversifier? }\end{array}$ & $\begin{array}{l}\text { Bouri, Molnar, Azzi, } \\
\text { Roubaud, \& Hagfors } \\
\text { (2017) }\end{array}$ & Finance Research Letters & 100 \\
\hline $\begin{array}{l}\text { Hedging capabilities of bitcoin. Is it the virtual } \\
\text { gold? }\end{array}$ & Dyhrberg (2016b) & Finance Research Letters & 97 \\
\hline On the inefficiency of Bitcoin & $\begin{array}{l}\text { Nadarajah \& Chu } \\
\text { (2017) }\end{array}$ & Economics Letters & 92 \\
\hline $\begin{array}{l}\text { The inefficiency of Bitcoin revisited: } A \text { dynamic } \\
\text { approach }\end{array}$ & Bariviera (2017) & Economics Letters & 87 \\
\hline Some stylized facts of the Bitcoin market & $\begin{array}{l}\text { Bariviera, Basgall, } \\
\text { Hasperue, \& Naiouf } \\
(2017)\end{array}$ & $\begin{array}{l}\text { Physica A-Statistical } \\
\text { Mechanics and Its } \\
\text { Applications }\end{array}$ & 80 \\
\hline $\begin{array}{l}\text { Can volume predict Bitcoin returns and } \\
\text { volatility? A quantiles-based approach }\end{array}$ & $\begin{array}{l}\text { Balcilar, Bouri, Gupta, } \\
\text { \& Roubaud (2017) }\end{array}$ & Economic Modelling & 75 \\
\hline $\begin{array}{l}\text { Bitcoin: Medium of exchange or speculative } \\
\text { assets? }\end{array}$ & $\begin{array}{l}\text { Baur, Hong, \& Lee } \\
(2018)\end{array}$ & $\begin{array}{l}\text { Journal of International } \\
\text { Financial Markets } \\
\text { Institutions \& Money }\end{array}$ & 59 \\
\hline Price clustering in Bitcoin & Urquhart (2017) & Economics Letters & 59 \\
\hline $\begin{array}{l}\text { Does Bitcoin hedge global uncertainty? } \\
\text { Evidence from wavelet-based quantile-in- } \\
\text { quantile regressions }\end{array}$ & $\begin{array}{l}\text { Bouri, Gupta, Tiwari, } \\
\text { \& Roubaud (2017) }\end{array}$ & Finance Research Letters & 55 \\
\hline $\begin{array}{l}\text { Informational efficiency of Bitcoin-An } \\
\text { extension }\end{array}$ & $\begin{array}{l}\text { Tiwari, Jana, Das, \& } \\
\text { Roubaud (2018) }\end{array}$ & Economics Letters & 47 \\
\hline Price manipulation in the Bitcoin ecosystem & Gandal, Hamrick, & Journal of Monetary & 46 \\
\hline
\end{tabular}




\begin{tabular}{|c|c|c|c|}
\hline & $\begin{array}{l}\text { Moore, \& Oberman } \\
(2018)\end{array}$ & Economics & \\
\hline $\begin{array}{l}\text { Datestamping the Bitcoin and Ethereum } \\
\text { bubbles }\end{array}$ & $\begin{array}{l}\text { Corbet, Lucey, \& } \\
\text { Yarovaya (2018) }\end{array}$ & Finance Research Letters & 43 \\
\hline $\begin{array}{l}\text { Price discovery of cryptocurrencies: Bitcoin } \\
\text { and beyond }\end{array}$ & $\begin{array}{l}\text { Brauneis \& Mestel } \\
(2018)\end{array}$ & Economics Letters & 37 \\
\hline $\begin{array}{l}\text { Long-range correlations and asymmetry in the } \\
\text { Bitcoin market }\end{array}$ & $\begin{array}{l}\text { Alvarez-Ramirez, } \\
\text { Rodriguez, \& Ibarra- } \\
\text { Valdez (2018) }\end{array}$ & $\begin{array}{l}\text { Physica A-Statistical } \\
\text { Mechanics and Its } \\
\text { Applications }\end{array}$ & 37 \\
\hline $\begin{array}{l}\text { Virtual relationships: Short- and long-run } \\
\text { evidence from BitCoin and altcoin markets }\end{array}$ & $\begin{array}{l}\text { Ciaian, Rajcaniova, \& } \\
\text { Kancs (2018) }\end{array}$ & $\begin{array}{l}\text { Journal of International } \\
\text { Financial Markets } \\
\text { Institutions \& Money }\end{array}$ & 35 \\
\hline $\begin{array}{l}\text { A survey on security and privacy issues of } \\
\text { Bitcoin }\end{array}$ & $\begin{array}{l}\text { Conti, Kumar, Lal, \& } \\
\text { Ruj (2018) }\end{array}$ & $\begin{array}{l}\text { IEEE Communications } \\
\text { Surveys and Tutorials }\end{array}$ & 33 \\
\hline $\begin{array}{l}\text { Time-varying long-term memory in Bitcoin } \\
\text { market }\end{array}$ & $\begin{array}{l}\text { Jiang, Nie, \& Ruan } \\
\text { (2018) }\end{array}$ & Finance Research Letters & 32 \\
\hline $\begin{array}{l}\text { Chaos, randomness and multi-fractality in } \\
\text { Bitcoin market }\end{array}$ & $\begin{array}{l}\text { Lahmiri \& Bekiros } \\
(2018)\end{array}$ & Chaos Solitons \& Fractals & 32 \\
\hline What causes the attention of Bitcoin? & Urquhart (2018) & Economics Letters & 30 \\
\hline $\begin{array}{l}\text { Bitcoin, gold and the US dollar - A replication } \\
\text { and extension }\end{array}$ & $\begin{array}{l}\text { Baur, Dimpfl, \& Kuck } \\
(2018)\end{array}$ & Finance Research Letters & 28 \\
\hline $\begin{array}{l}\text { Does economic policy uncertainty predict the } \\
\text { Bitcoin returns? An empirical investigation }\end{array}$ & $\begin{array}{l}\text { Demir, Gozgor, Lau, } \\
\text { \& Vigne (2018) }\end{array}$ & Finance Research Letters & 27 \\
\hline Bitcoin returns and transaction activity & Koutmos (2018) & Economics Letters & 18 \\
\hline $\begin{array}{l}\text { Portfolio diversification with virtual currency: } \\
\text { Evidence from bitcoin }\end{array}$ & $\begin{array}{l}\text { Guesmi, Saadi, Abid, } \\
\text { \& Ftiti (2019) }\end{array}$ & $\begin{array}{l}\text { International Review of } \\
\text { Financial Analysis }\end{array}$ & 16 \\
\hline $\begin{array}{l}\text { The inefficiency of Bitcoin revisited: } A \text { high- } \\
\text { frequency analysis with alternative currencies }\end{array}$ & Sensoy (2019) & Finance Research Letters & 14 \\
\hline $\begin{array}{l}\text { Sex, drugs, and Bitcoin: How much illegal } \\
\text { activity is financed through cryptocurrencies? }\end{array}$ & $\begin{array}{l}\text { Foley, Karlsen, \& } \\
\text { Putnins (2019) }\end{array}$ & $\begin{array}{l}\text { Review of Financial } \\
\text { Studies }\end{array}$ & 12 \\
\hline Does twitter predict Bitcoin? & $\begin{array}{l}\text { Shen, Urquhart, \& } \\
\text { Wang (2019) }\end{array}$ & Economics Letters & 11 \\
\hline
\end{tabular}

We pointed out that our sample's most cited article, with 192 citations in Web of Science in three years, was the one of Tschorsch \& Scheuermann (2016) and that the journals with more cited papers were Economics Letters (11 papers with a total of 791 citations) and Finance Research Letters (9 papers with a total of 528 citations).

In brief, the 'highly cited` bitcoin papers are in a great measure articles in the economic field, that:

- present the bitcoin platform's design principles and properties for a nontechnical audience and the economic implications especially for the financial system: Bohme, Christin, Edelman, \& Moore (2015);

- $\quad$ analyse the volatility of bitcoin prices using autoregressive conditional heteroskedastic (GARCH) or stochastic volatility models: Dyhrberg (2016a); Katsiampa (2017); Balcilar, Bouri, Gupta, \& Roubaud (2017); Bouri, Molnar, Azzi, Roubaud, \& Hagfors (2017); Baur, Dimpfl, \& Kuck (2018); Guesmi, Saadi, Abid, \& Ftiti (2019);

- model the bitcoin prices: Cheah \& Fry (2015); Ciaian, Rajcaniova, \& Kancs (2016); Urquhart (2017); Corbet, Lucey, \& Yarovaya (2018); Brauneis \& Mestel (2018); Lahmiri \& Bekiros (2018);

- explore the hedging capabilities of bitcoin by applying the asymmetric GARCH methodology (Dyhrberg, 2016b) or the quantile-on-quantile regression (Bouri, Gupta, Tiwari, \& Roubaud 2017); 
- $\quad$ study the market efficiency of bitcoin: Urquhart (2016); Nadarajah \& Chu (2017); Bariviera (2017); Tiwari, Jana, Das, \& Roubaud (2018); Alvarez-Ramirez, Rodriguez, \& Ibarra-Valdez (2018); Jiang, Nie, \& Ruan (2018); Sensoy (2019);

- compare bitcoin and standard currencies dynamics: Bariviera, Basgall, Hasperue, \& Naiouf (2017);

- analyse the bitcoin as a medium of exchange and as an speculative asset: Baur, Hong, \& Lee (2018);

- examine the interdependencies between bitcoin and other cryptocurrencies: Ciaian, Rajcaniova, \& Kancs (2018);

- explore the relationship between investor attention and bitcoin fundamentals (Urquhart, 2018) or returns (Shen, Urquhart, \& Wang, 2019);

- study the empirical linkages between bitcoin returns and transaction activity (Koutmos, 2018) or economic policy (Demir, Gozgor, Lau, \& Vigne, 2018);

- $\quad$ analyse the impact of suspicious trading activity: Gandal, Hamrick, Moore, \& Oberman (2018); Foley, Karlsen, \& Putnins (2019).

The two technical articles are surveys that cover the bitcoin protocol and its applications (Tschorsch \& Scheuermann, 2016) and the security and privacy aspects of bitcoin (Conti, Kumar, Lal, \& Ruj, 2018).

\section{Data visualization}

For data visualization we have chosen VOSviewer software to construct different maps represented by a network of items: the size of the circle depends on the item importance; the network connections show the closeness of the link between items; the locations of the circles and colours are used to cluster the items.

First, we used VOSviewer to create a term co-occurrence map based on text data. From 12880 terms extracted from title and abstract fields, we selected 714 with 5 minimum occurrences of a term. For each, in a binary counting mode, the program calculated a relevance score and selected the most relevant terms (428).

On the map (Figure 3) we can observe 3 clusters: (1) economics and finance; (2) computer science and (3) engineering. The right part of the map covers economics and finance issues (green) and the left side is more related to computer science and engineering (red and blue).

Secondly, using VOSviewer we have created various maps based on bibliographic data to construct 4 types of network:

\section{I. co-authorship}

Analysis of the co-authorship seeks to examine the links between authors and the authors' countries distribution. For each of 1791 authors, the program calculated the total strength of the co-authorship links with other authors and selected the authors with the greatest total link strength. The largest set of connected items consists of 61 authors, as can be seen in Figure 4. 
Figure 3. Map of terms in title and abstract fields (binary counting)

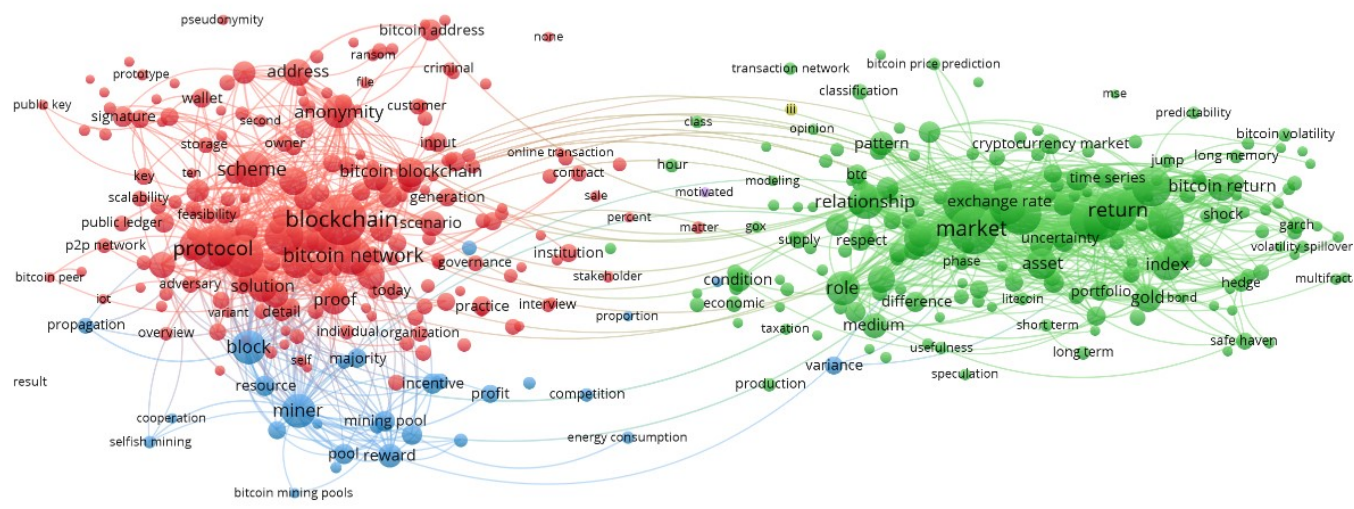

\& $\AA^{\circ}$ vosviewer

Figure 4. Map of authors

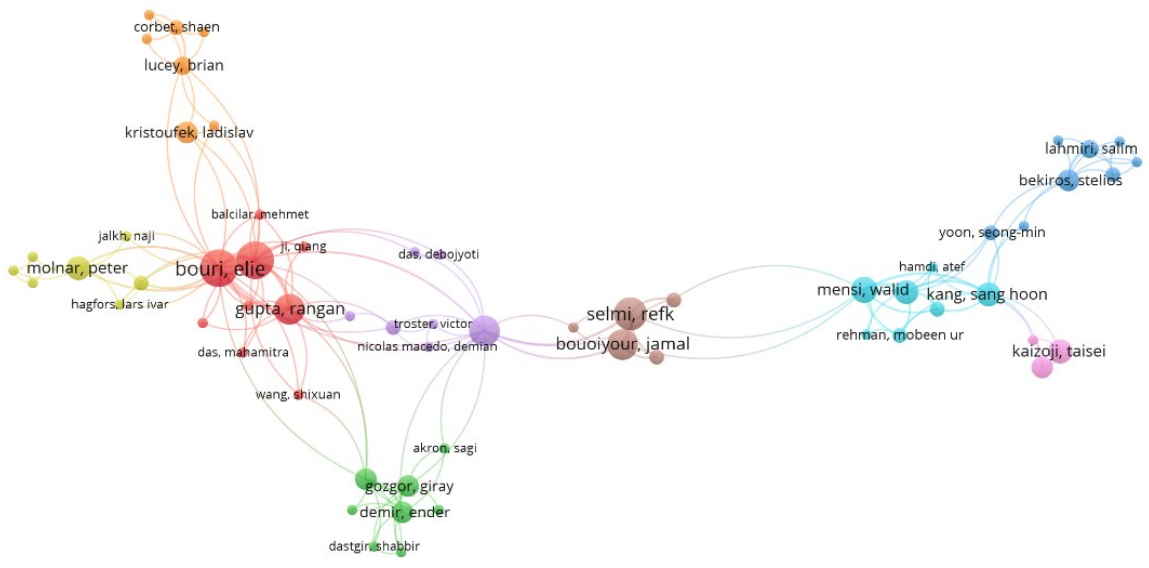

fon vosviewer

In Figure 5 is represented the corresponding author's countries distribution, with 65 countries most connected from a total of 78 countries. 
Figure 5. Map of corresponding author's countries

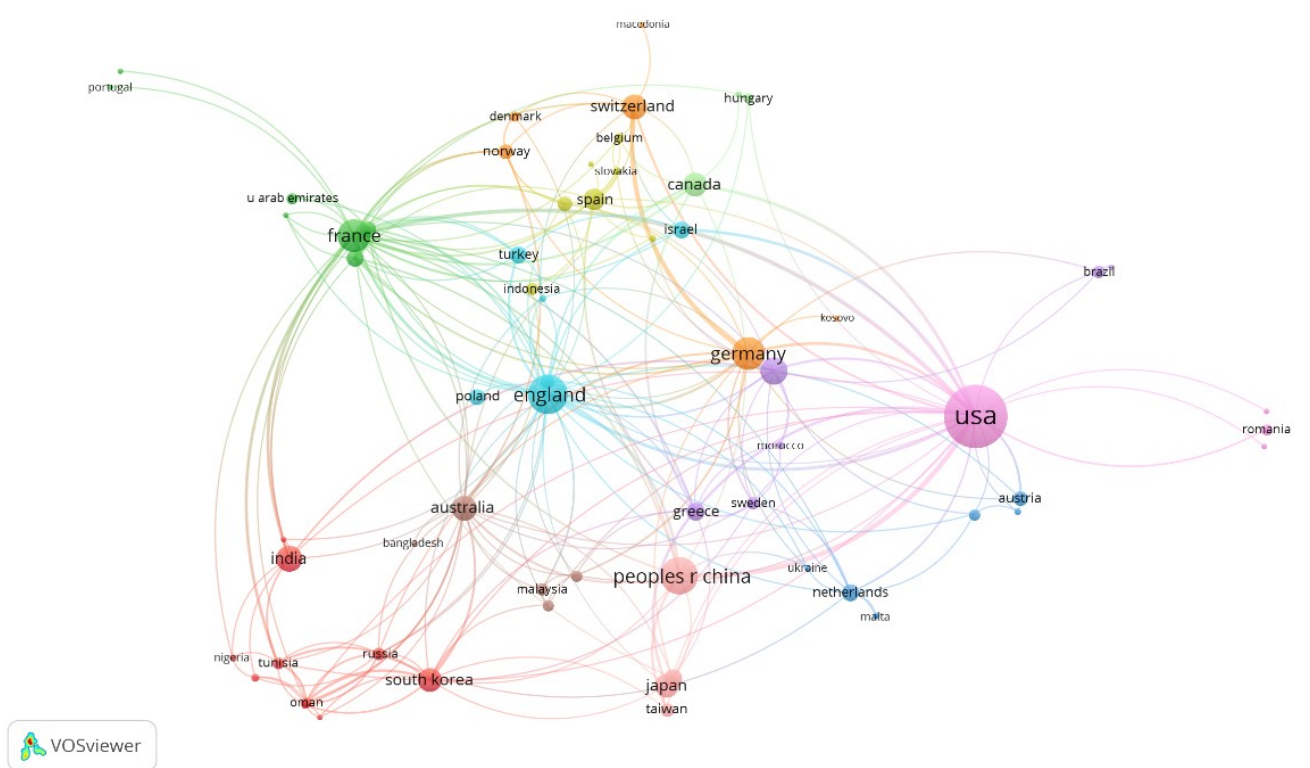

II. co-occurrence of the authors' keywords

Analysis of the co-occurrence of keywords aims to study the conceptual structure of the research field. For each of 1451 keywords, the program calculated the total strength of the co-occurrence and selected the keywords with the greatest link strength. In a full counting mode, the largest set of connected items consists of 994 keywords.

Figure 6 shows ten most used keywords by the authors in the bitcoin articles: bitcoin, blockchain, cryptocurrency, cryptocurrencies, digital currency, money, anonymity, virtual currency, volatility and security. We observed that bitcoin is the most used keyword and that it connects strongly with the rest of the keywords, especially with blockchain and cryptocurrency.

\section{III. citation}

Analysis of the papers' citations intends to show the structure and connections of papers that are cited more frequently. For each of 897 papers, the program extracted 524 papers with minimum 1 citation and selected 459 papers with the greatest total link strength. Figure 7 displays the most cited papers by using circle symbols of different sizes and colours. The map highlights the 'highly cited papers' and is consistent with the results presented in Table 6.

\section{IV. co-citation}

Another unit of analysis is co-citation of sources, that aims to identify the most cited journals. From 9263 cited sources, the program extracted 609 with 5 minimum citations of a source, calculated the total strength of co-citation links and selected sources with the greatest total link strength. 
Figure 6. Map of keywords (full counting)

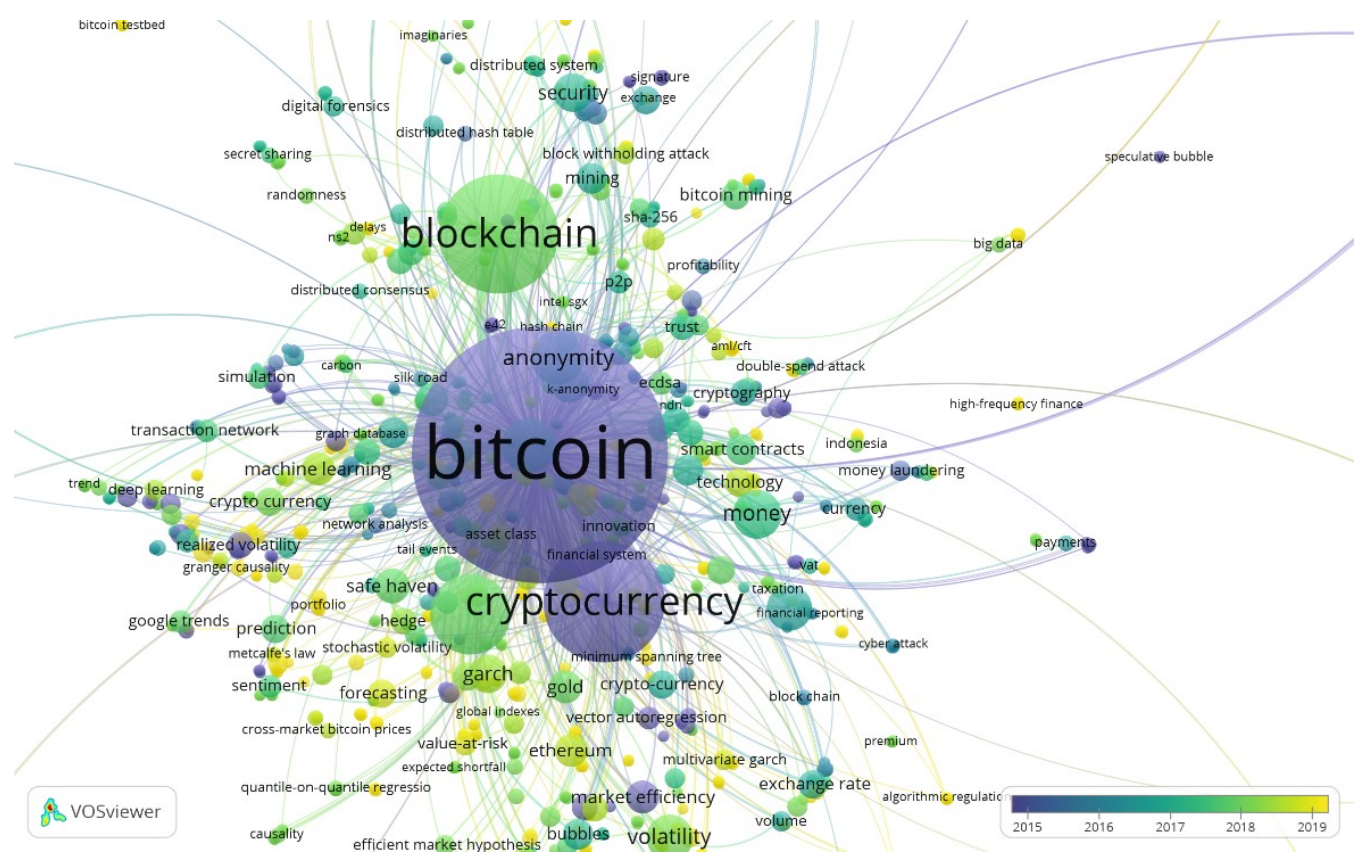

Figure 7. Map of papers`citations

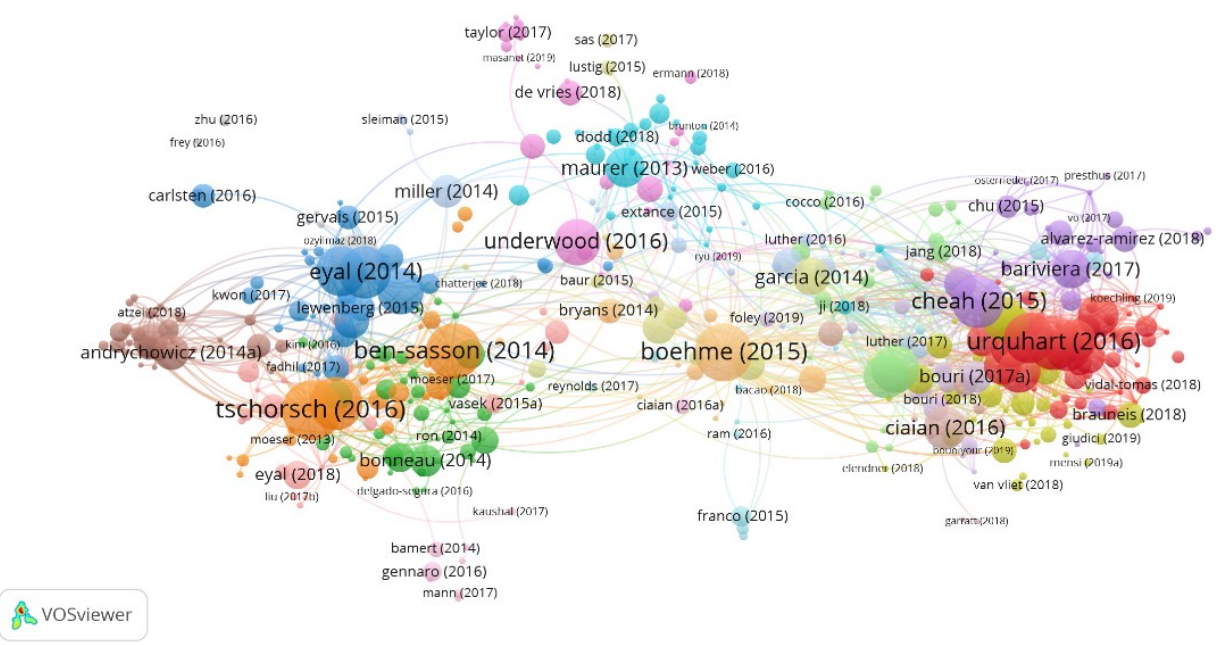


Figure 8. Map of journals`co-citation

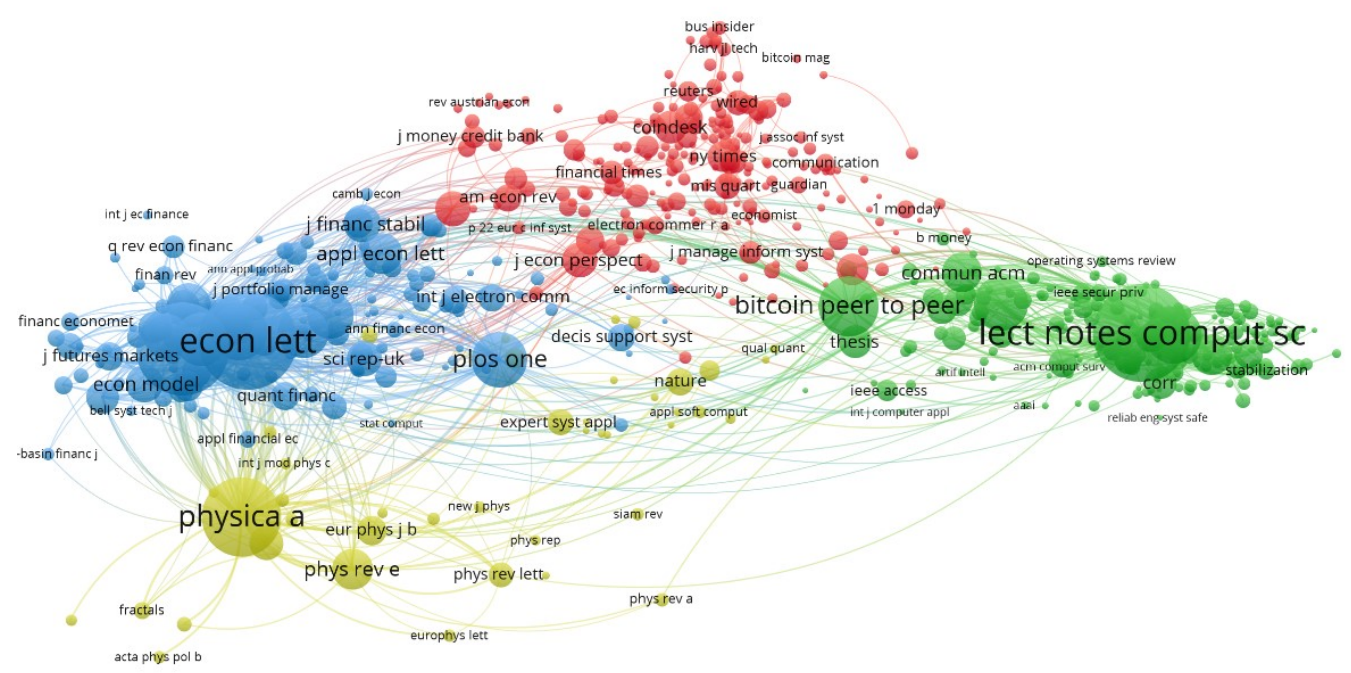

\& vosviewer

On the map (Figure 8) we can identify 4 clusters, that are linked to scientific fields (finance, computer science, economics and physics) and several journals with multiple connections: Economic Letters, Finance Research Letters, Physica A-Statistical Mechanics and Its Applications, Lecture Notes in Computer Science.

\section{Conclusions}

The purpose of this paper was to evaluate bitcoin literature based on the structures and networks of science, as a first step in the research of this new phenomenon. We systematised the growing scientific literature on bitcoin published in the period 20122019 and gave useful insights on academic research in this field regarding publication year, type and category, authors, journals and citations.

Our analysis provides a knowledge area map that identifies and evaluates the links between authors and countries distribution, the conceptual structure of the field, the structure and connections of most cited papers and journals.

The bitcoin bibliometric study indicates that our sample's most cited article, with 192 citations in Web of Science in three years, was the one of Tschorsch \& Scheuermann (2016) and that the journals with more cited papers were Economics Letters and Finance Research Letters. In our sample, $51.4 \%$ of papers are articles published in scientific journals and $37.5 \%$ are Proceedings papers. USA is the country whose authors have published highest number of papers $(23.8 \%)$, followed by United Kingdom $(9.4 \%)$ and China (8.6\%). We observe that bitcoin is the most common keyword and that it connects strongly with other keywords, like blockchain and cryptocurrency. Moreover, bitcoin papers are concentrated around three main fields - computer science (54.1\%); economics, 
business and finance (33.5\%); and engineering (12.7\%) - reflecting the interdisciplinarity of this research area.

This research is limited to bitcoin, as the most used cryptocurrency and having the highest market capitalization. Future research should further develop to include other cryptocurrencies and to use different data sources (Scopus, SpringerLink etc.).

\section{References:}

Alvarez-Ramirez, J., Rodriguez, E., \& Ibarra-Valdez, C. (2018). Long-range correlations and asymmetry in the Bitcoin market. Physica a-Statistical Mechanics and Its Applications, 492, 948-955. doi:10.1016/j.physa.2017.11.025

Aria, M., \& Cuccurullo, C. (2017). bibliometrix: An R-tool for comprehensive science mapping analysis. Journal of Informetrics, 11(4), 959-975. doi:10.1016/j.joi.2017.08.007

Balcilar, M., Bouri, E., Gupta, R., \& Roubaud, D. (2017). Can volume predict Bitcoin returns and volatility? A quantiles-based approach. Economic Modelling, 64, 74-81. doi:10.1016/j.econmod.2017.03.019

Bariviera, A. F. (2017). The inefficiency of Bitcoin revisited: A dynamic approach. Economics Letters, 161, 1-4. doi:10.1016/j.econlet.2017.09.013

Bariviera, A. F., Basgall, M. J., Hasperue, W., \& Naiouf, M. (2017). Some stylized facts of the Bitcoin market. Physica a-Statistical Mechanics and Its Applications, 484, 82-90. doi:10.1016/j.physa.2017.04.159

Baur, D. G., Dimpfl, T., \& Kuck, K. (2018). Bitcoin, gold and the US dollar - A replication and extension. Finance Research Letters, 25, 103-110. doi:10.1016/j.frl.2017.10.012

Baur, D. G., Hong, K., \& Lee, A. D. (2018). Bitcoin: Medium of exchange or speculative assets? Journal of International Financial Markets Institutions \& Money, 54, 177-189. doi:10.1016/j.intfin.2017.12.004

Bohme, R., Christin, N., Edelman, B., \& Moore, T. (2015). Bitcoin: Economics, Technology, and Governance. Journal of Economic Perspectives, 29(2), 213-238. doi:10.1257/jep.29.2.213

Bouri, E., Gupta, R., Tiwari, A. K., \& Roubaud, D. (2017). Does Bitcoin hedge global uncertainty? Evidence from wavelet-based quantile-in-quantile regressions. Finance Research Letters, 23, 87-95. doi:10.1016/j.frl.2017.02.009

Bouri, E., Molnar, P., Azzi, G., Roubaud, D., \& Hagfors, L. I. (2017). On the hedge and safe haven properties of Bitcoin: Is it really more than a diversifier? Finance Research Letters, 20, 192198. doi:10.1016/j.fri.2016.09.025

Brauneis, A., \& Mestel, R. (2018). Price discovery of cryptocurrencies: Bitcoin and beyond. Economics Letters, 165, 58-61. doi:10.1016/j.econlet.2018.02.001

Cheah, E. T., \& Fry, J. (2015). Speculative bubbles in Bitcoin markets? An empirical investigation into the fundamental value of Bitcoin. Economics Letters, 130, 32-36. doi:10.1016/j.econlet.2015.02.029

Ciaian, P., Rajcaniova, M., \& Kancs, D. (2016). The economics of BitCoin price formation. Applied Economics, 48(19), 1799-1815. doi:10.1080/00036846.2015.1109038

Ciaian, P., Rajcaniova, M., \& Kancs, D. (2018). Virtual relationships: Short- and long-run evidence from BitCoin and altcoin markets. Journal of International Financial Markets Institutions \& Money, 52, 173-195. doi:10.1016/j.intfin.2017.11.001

CoinMarketCap. Online database. Retrieved November 2019 https://coinmarketcap.com/

Conti, M., Kumar, E. S., Lal, C., \& Ruj, S. (2018). A Survey on Security and Privacy Issues of Bitcoin. leee Communications Surveys and Tutorials, 20(4), 3416-3452. doi:10.1109/comst.2018.2842460 
Corbet, S., Lucey, B., \& Yarovaya, L. (2018). Datestamping the Bitcoin and Ethereum bubbles. Finance Research Letters, 26, 81-88. doi:10.1016/j.frl.2017.12.006

Demir, E., Gozgor, G., Lau, C. K. M., \& Vigne, S. A. (2018). Does economic policy uncertainty predict the Bitcoin returns? An empirical investigation. Finance Research Letters, 26, 145-149. doi:10.1016/j.frl.2018.01.005

Dyhrberg, A. H. (2016a). Bitcoin, gold and the dollar - A GARCH volatility analysis. Finance Research Letters, 16, 85-92. doi:10.1016/j.frl.2015.10.008

Dyhrberg, A. H. (2016b). Hedging capabilities of bitcoin. Is it the virtual gold? Finance Research Letters, 16, 139-144. doi:10.1016/j.frl.2015.10.025

Foley, S., Karlsen, J. R., \& Putnins, T. J. (2019). Sex, Drugs, and Bitcoin: How Much Illegal Activity Is Financed through Cryptocurrencies? Review of Financial Studies, 32(5), 1798-1853. doi:10.1093/rfs/hhz015

Gandal, N., Hamrick, J. T., Moore, T., \& Oberman, T. (2018). Price manipulation in the Bitcoin ecosystem. Journal of Monetary Economics, 95, 86-96. doi:10.1016/j.jmoneco.2017.12.004

Guesmi, K., Saadi, S., Abid, I., \& Ftiti, Z. (2019). Portfolio diversification with virtual currency: Evidence from bitcoin. International Review of Financial Analysis, 63, 431-437. doi:10.1016/j.irfa.2018.03.004

Holub, M., \& Johnson, J. (2018). Bitcoin research across disciplines. Information Society, 34(2), 114126. doi:10.1080/01972243.2017.1414094

Jiang, Y. H., Nie, H., \& Ruan, W. H. (2018). Time-varying long-term memory in Bitcoin market. Finance Research Letters, 25, 280-284. doi:10.1016/j.frl.2017.12.009

Katsiampa, P. (2017). Volatility estimation for Bitcoin: A comparison of GARCH models. Economics Letters, 158, 3-6. doi:10.1016/j.econlet.2017.06.023

Koutmos, D. (2018). Bitcoin returns and transaction activity. Economics Letters, 167, 81-85. doi:10.1016/j.econlet.2018.03.021

Lahmiri, S., \& Bekiros, S. (2018). Chaos, randomness and multi-fractality in Bitcoin market. Chaos Solitons \& Fractals, 106, 28-34. doi:10.1016/j.chaos.2017.11.005

Liu, J. (2016). Bitcoin literature: a co-word analysis. Paper presented at the 6th Economics \& Finance Conference, OECD Paris.

Merediz-Sola, I., \& Bariviera, A. F. (2019). A bibliometric analysis of bitcoin scientific production. Research in International Business and Finance, 50, 294-305. doi:10.1016/j.ribaf.2019.06.008

Nadarajah, S., \& Chu, J. (2017). On the inefficiency of Bitcoin. Economics Letters, 150, 6-9. doi:10.1016/j.econlet.2016.10.033

Nakamoto, S. (2008). Bitcoin: A Peer-to-Peer Electronic Cash System.

Sensoy, A. (2019). The inefficiency of Bitcoin revisited: A high-frequency analysis with alternative currencies. Finance Research Letters, 28, 68-73. doi:10.1016/j.frl.2018.04.002

Shen, D. H., Urquhart, A., \& Wang, P. F. (2019). Does twitter predict Bitcoin? Economics Letters, 174, 118-122. doi:10.1016/j.econlet.2018.11.007

Tiwari, A. K., Jana, R. K., Das, D., \& Roubaud, D. (2018). Informational efficiency of Bitcoin-An extension. Economics Letters, 163, 106-109. doi:10.1016/j.econlet.2017.12.006

Tiwari, A. K., Kumar, S., \& Pathak, R. (2019). Modelling the dynamics of Bitcoin and Litecoin: GARCH versus stochastic volatility models. Applied Economics, 51(37), 4073-4082. doi:10.1080/00036846.2019.1588951

Tschorsch, F., \& Scheuermann, B. (2016). Bitcoin and Beyond: A Technical Survey on Decentralized Digital Currencies. leee Communications Surveys and Tutorials, 18(3), 2084-2123. doi:10.1109/comst.2016.2535718

Urquhart, A. (2016). The inefficiency of Bitcoin. Economics Letters, 148, 80-82. doi:10.1016/j.econlet.2016.09.019 
Urquhart, A. (2017). Price clustering in Bitcoin. Economics Letters, 159, 145-148. doi:10.1016/j.econlet.2017.07.035

Urquhart, A. (2018). What causes the attention of Bitcoin? Economics Letters, 166, 40-44. doi:10.1016/j.econlet.2018.02.017

van Eck, N. J., \& Waltman, L. (2010). Software survey: VOSviewer, a computer program for bibliometric mapping. Scientometrics, 84(2), 523-538. doi:10.1007/s11192-009-0146-3 